\title{
Corporate governance and the informativeness of disclosures in Australia: A re-examination
}

\author{
Wendy Beekes ${ }^{1}$, Philip Brown, and Qiyu Zhang* \\ Forthcoming in Accounting and Finance
}

* Wendy Beekes is from Lancaster University, Philip Brown is from the Universities of New South Wales and Western Australia, and Qiyu Zhang is from Lancaster University.

JEL: G30; G38; M40.

Keywords: Corporate governance; Disclosures; Price discovery; Timeliness; Transparency

\footnotetext{
${ }^{1}$ Address for correspondence: Dr Wendy Beekes, Department of Accounting and Finance, Management School, Lancaster University, Lancashire, LA1 4YX, UK. Email: w.beekes@lancaster.ac.uk. Tel: +44 (0) 1524593623 , Fax: +44 (0) 1524847321
}

\section{ACKNOWLEDGEMENTS}

We thank Jim Psaros for providing us with the Horwath/WHK Horwath corporate governance datasets. We thank Kwok Tong Soo, two anonymous referees and the editor for useful comments received on previous drafts of the paper. Wendy Beekes and Philip Brown acknowledge funding from the Leverhulme Trust (Grant reference: F/00 185/W - Corporate governance, disclosure policies and the timeliness of price discovery). 


\title{
Corporate governance and the informativeness of disclosures in Australia: A re-examination
}

\begin{abstract}
We re-examine the association between corporate governance and disclosures reported by Beekes and Brown (2006), using an extended time series of Australian data. Since the ASX corporate governance guidelines were introduced in 2003, firms generally have increased their disclosure frequency and demonstrated an improvement in the timeliness of bad news relative to good news, indicating a levelling of disclosure practices and greater transparency. Better governed firms have become more cautious in their disclosure practices. However they continue to be more balanced with respect to good and bad news timeliness. Changes to disclosure laws have also influenced company practices.
\end{abstract}




\section{Introduction}

Formal disclosures are an important medium through which firms signal private information to the market. Greater disclosure has the potential to reduce a firm's cost of capital (Botosan, 1997) and can limit costly litigation for inadequate disclosure of impending bad news (Skinner, 1994). Corporate governance (CG) policies are believed to influence the level of disclosure and the firm's transparency. Although higher CG quality ${ }^{1}$ could substitute for greater disclosure (firms that adopt stronger governance measures make fewer disclosures), it could be complementary (controlling shareholders may find it advantageous if the firm adopts weaker governance measures and is less transparent). Evidence on whether CG and disclosure are complements or substitutes is mixed. Eng and Mak (2003) find less disclosure by firms with greater outside director board membership (typically an indicator of stronger governance) in Singapore, but Bassett, Koh and Tutticci (2007), Lim, Matolcsy and Chow (2007) and Beekes and Brown (2006) find a complementary association for Australian firms.

Our knowledge of relationships between CG and disclosure is still limited, particularly with respect to how changes in CG guidelines and in the law affect the firm's public disclosures and its market transparency. To investigate these two aspects further, we study Australian firms over the period 2001-2008. We study CG in Australia as there has been a Continuous Disclosure (CD) statutory requirement since 1994, and excellent data are available on the content of all announcements made by listed companies to the Australian Stock Exchange (ASX) and precisely when the ASX released them to the market. ${ }^{2}$ Legal cases brought by the Australian Securities and Investments Commission (ASIC) and other enforcement actions by

\footnotetext{
${ }^{1}$ We take higher quality CG to mean 'better' CG, which is shorthand for a greater degree of compliance with an authoritative set of CG principles or guidelines. In this study, by stating 'better' CG we are referring to the firm being scored more highly according to the Horwath CG ratings for Australian firms (see below).

2 "Continuous disclosure is the timely advising of information to keep the market informed of events and developments as they occur. Information for release to the market must be given to ASX's company announcements office" for release to the market before it is released publicly (ASX, 2012, p.301; see also Brown, Taylor and Walter, 1999; Brown, Howitt and Wee, 2005; Matolcsy, Tyler and Wells, 2012). Continuous disclosure is a statutory requirement monitored and enforced jointly by the ASX and the Commonwealth government regulator, the Australian Securities and Investments Commission (ASIC).
} 
ASIC indicate compliance with $\mathrm{CD}$ is less than complete and that the role of $\mathrm{CG}$ in determining firms' disclosure practices remains an issue. ${ }^{3}$ The relevance of our sample period is highlighted by two events: the introduction in 2003 of the ASX's 'Principles of Good Governance and Best Practice Recommendations', hereafter the ASX CG Code; and provisions in the 2004 Commonwealth Corporate Reporting and Disclosure Laws (CLERP 9). Another reason for choosing Australia is that our findings should apply in other countries with established equity markets and a comparable CG code, such as Canada and the UK.

We contribute to the literature on CG and disclosure in several ways. First, by reverting to methods pioneered by Fama, Fisher, Jensen and Roll (1969) and introduced to the accounting literature by Ball and Brown (1968), we provide stark evidence that differences in CG ratings are related to the average speed of longer-term price discovery ("timeliness", in Ball and Brown's terminology). Second, building on foundations laid by Beekes and Brown (2006), hereafter BB06, we employ a battery of multivariate tests that collectively provide evidence that $\mathrm{CG}$ and disclosures by Australian firms are linked but that the link has attenuated over time. Although the BB06 results have been widely cited, ${ }^{4}$ they were limited to one year of CG data and their applicability to a longer time frame has not been demonstrated. As Brown (2013a) comments, replicating such studies is justified if it clarifies their external validity.

Given the intervening years since the BB06 study was undertaken and the methodological, institutional and legislative changes that have taken place, we improve substantially on BB06 by extending the study period to eight years of governance data (2001-2008), by refining the dependent variables, by re-specifying their models, and by adopting better estimators. In the process, we address Clubb's (2006) comments on endogeneity and the need to examine timeliness of price discovery in both good and bad news periods. Our third contribution is to

\footnotetext{
${ }^{3}$ For example, James Hardie Industries, Fortescue Metals and Centro (ASIC, 2011a, 2011b, 2012).

${ }^{4}$ According to Harzing's Publish or Perish software (available from http://www.harzing.com/pop.htm), BB06 had been cited 192 times by mid-May 2014.
} 
show that, while the transparency and the timeliness of disclosures do differ significantly across firms according to their governance practices, inasmuch as there appear to be intrayear changes in behaviour, the relationship between CG and market transparency may be more subtle than previously thought. Fourth, we contribute directly to the regulatory debate on the importance of $\mathrm{CG}$ for firms' disclosure policies and their transparency in equity markets by re-affirming the practitioner view, as reflected in the ASX CG Code, that better governed firms are more forthcoming and more balanced in their disclosures.

In sum, we find firms with better CG are priced more efficiently (i.e., news is priced earlier) in equity markets than poorly governed firms, although good news is priced earlier for poorly governed firms. Correspondingly, bad news is priced more efficiently for better governed firms. The ASX CG Code of 2003 appears to have levelled disclosure practices across firms, with greater document disclosure and more balanced share market pricing of good relative to bad news. Despite the levelling, better governed firms can still signal their quality by being more conservative with respect to good news timeliness. Additional sanctions placed upon firms and individuals by CLERP 9 may have made firms more cautious when disclosing information, with fewer price sensitive disclosures and less timely pricing of good and bad news.

The remainder of our paper is organised as follows. Section 2 reviews relevant literature and develops our hypotheses. Section 3 discusses the data, and is followed by a description, in Section 4, of our research methods. Section 5 contains the results and summarises their robustness. Section 6 contains our conclusions.

\section{Hypotheses}

\subsection{Background}


While Australian firms are legally required to release price sensitive information to the market on a timely basis, even without a legal requirement they would have an incentive to disclose information to signal their quality and avoid Akerlof's (1970) 'lemons' problem. Disclosure can be valuable to the firm as it may reduce the cost of capital (Botosan, 1997). It can also be important when seeking the attention of potential investors. For example, Collett and Hrasky (2005) find more comprehensive disclosures of CG practices in company annual reports for firms raising additional share capital, prior to a requirement to do so.

However, complete (full) disclosure is unlikely to be optimal (Hermalin and Weisbach, 2012) and firms may decide to retain some private information within the firm, possibly due to their close ownership structures or for fear of losing a competitive advantage. Reputedly U.S. managers delay the disclosure of bad news relative to good news (Kothari, Shu and Wysocki, 2009), despite the risk of costly litigation if bad news is withheld (Skinner, 1994). There may be a loss of reputational capital if managers become known for early disclosures of less precise or unconfirmed good news, or for withholding bad news from the market until either all reasonable avenues for reversing the bad news are exhausted or an impending mandatory reporting deadline leaves them with little choice. ${ }^{5}$ Given this background, we focus on whether CG has a bearing on firms' disclosure policies and their outcomes.

\subsection{Disclosure frequency and corporate governance}

Although additional disclosures may be a substitute for better CG structures, prior research on Australian companies indicates CG quality and disclosures are complementary even when disclosures are mandatory (Kent and Stewart, 2008; Nelson, Gallery and Percy, 2010). ${ }^{6}$ Given BB06 found better CG in Australian firms was associated with greater frequency of

\footnotetext{
${ }^{5}$ Gong (2007) and Kothari et al. (2009) summarise various motives for this behaviour by managers.

${ }^{6} \mathrm{Lim}$ et al. (2007, p.578) claim the association between a core component of CG and disclosures holds only for certain types of disclosure. They find board independence is influential only on "forward looking and quantitative information" and there is no relationship for "non-financial and financial voluntary disclosure" in Australian firms' 2001 annual reports.
} 
disclosure to the ASX, we likewise predict better governed Australian firms lodge more documents with the ASX.

$H_{1}$ : Firms with better CG lodge more documents with the ASX.

\subsection{Timeliness of price discovery and corporate governance}

Timeliness is an important characteristic for information to be useful to an investor's decision making process. The timeliness of price discovery refers to how quickly market sensitive information is incorporated into the firm's share price and is a measure of transparency (BB06). The ASX's alert system monitors price and volume changes and the ASX will query a firm if a significant price change or increase in volume traded has no apparent explanation. A substantial share price 'penalty' can be imposed by the market on a firm when the market learns the ASX has queried the firm about an unexplained price increase and the firm offers no explanation in its response. ${ }^{7}$ Thus firms have an incentive to monitor price movements and a statutory obligation to ensure price sensitive news is disclosed appropriately before it leaks to the market. If the directors of better governed firms are more diligent in monitoring market behaviour and meeting their statutory obligations, they will release information in a more timely fashion and we would expect their information to be reflected in share prices on a more timely basis (i.e. more quickly). Consistent with this view, BB06 find evidence of timelier price discovery for better governed Australian firms. Thus we likewise predict:

$\mathrm{H}_{2}$ : Price discovery is more timely (faster) for firms with better CG.

\subsection{Timeliness of good and bad news, and corporate governance}

Better governed Australian firms generally take a more conservative approach to income recognition (Ahmed and Henry, 2012). If their conservatism extends to news recognition, then the market pricing of good news for firms with better CG would be decelerated; i.e., it

\footnotetext{
${ }^{7}$ Based on data from July 1998-June 2000 and January 2010-April 2012, around 90\% of queries have been due to unexplained price increases (Gong, 2007; Drienko and Sault, 2013).
} 
would be reflected in their stock prices later than would be the case for poorly governed firms. With regard to bad news, better governed firms will 'get bad news out' earlier than poorly governed firms. This behaviour is consistent with the ASX CG Code proposition that better governed firms are more balanced in their disclosures of good and bad news (see below, section 2.6) and it supports the following three predictions:

$H_{3}$ : The timeliness of good news is slower for firms with better CG than for firms with weaker CG.

$H_{4:}$ The timeliness of bad news is faster for firms with better CG than for firms with weaker $C G$.

$H_{5}$ : For firms with weaker CG, the timeliness of good news is faster than bad news.

\subsection{Timeliness of document releases and corporate governance}

As noted earlier, the timing and nature of company announcements remain subject to significant discretion on the part of management. There is already evidence that firms with more independent boards are less likely to engage in earnings management or fraud (Beasley, 1996) and may improve the timeliness of price discovery (BB06). Consistent with prior research, we expect closer monitoring provided by a board that is more independent (which will be reflected in a higher overall $\mathrm{CG}$ rating) results in more timely lodgement of documents with the ASX:

$H_{6}$ : Firms with better CG lodge their documents with the ASX on a more timely basis.

\subsection{Changes to regulation}

The ASX CG Code was first published in 2003 and contained 10 key principles of good CG. Importantly, the code refers to timely and balanced disclosure (Principle 5), proposing "all investors have equal and timely access to material information concerning the company" and “company announcements are factual and presented in a clear and balanced way. 'Balance' 
requires the disclosure of both positive and negative information" (ASX Corporate Governance Council, 2003, p. 35). Acknowledging that a 'one size fits all approach' is inappropriate, beginning in 2003 firms listed on the ASX have been required to either disclose that they complied with the $10 \mathrm{CG}$ principles or explain where their practices departed from them (Hamilton, 2004). ${ }^{8}$ Given this focus, we would expect to find stronger evidence supporting H1-H6 since the Code was promulgated in 2003.

CLERP 9 took effect from 1 July 2004. Its CG provisions included requiring formal statements on the integrity of the financial statements by the CEO and CFO and, while the provision of non-audit services by external auditors was not prohibited, if those services were provided then the reasons why the auditor's independence is unaffected should be disclosed. Penalties for non-compliance with the $\mathrm{CD}$ regime were raised: individuals involved in a firm's failure to disclose material information became personally liable, firms became subject to an increase from AUD200,000 to AUD1,000,000 in the maximum penalty for a breach of the CD provisions, and the enforcement powers of ASIC with respect to such matters were enhanced. These provisions may also have resulted in stronger support for H1-H6.

\section{Data}

Our primary sample, of 1,994 firm-years, comprises data for Australian listed companies with CG ratings in the Horwath reports published annually from 2002 to $2009 .{ }^{9}$ Financial and Industrial Sector data were collected from a variety of sources, as explained below, and matched to this primary sample to yield a final sample of 1,487 firm-years.

\subsection{Measuring corporate governance}

\footnotetext{
${ }^{8}$ There is a specific requirement for firms included in the S\&P/ASX All Ordinaries Index to have an audit committee, under listing rule 12.7 (ASX Corporate Governance Council, 2003). Some relatively minor changes to $\mathrm{CG}$ guidance were made in 2007 when an updated CG code was issued by the ASX Corporate Governance Council, to apply to financial years after 1 January 2008 (ASX Corporate Governance Council, 2007).

${ }^{9}$ The CG reports we use initially were published by Horwath (2002-2006) and subsequently by WHK Horwath (2007-2009). The ratings were compiled at the University of Newcastle, Australia.
} 
We use the ratings in the Horwath reports to measure CG. The reports aim "to provide concrete evidence on Australian CG practice by focusing on objective, publicly available and measurable aspects of good governance" (WHK Horwath, 2008: p. 6). The ratings reflect information in the firm's annual report for the previous financial year. Prior work has used specific components of CG (e.g. the proportion of non-executive directors) to indicate better $\mathrm{CG}$, whereas the Horwath measure has the twin advantages of being more comprehensive and collected on a consistent basis. The reports are confined to Australian companies and have greater coverage than other databases such as Risk Metrics.

Each Horwath report contains CG rankings and 'star' ratings (ranging from a single star up to 5 stars) for the top 250 Australian listed companies by market capitalisation on 30 June of the previous year. ${ }^{10}$ Rankings reflect the degree of independence (i.e. the level of independent non-executive director membership) of the board and its main committees (Audit, Remuneration and Nomination), among other things. Particular regard is paid to aspects that have been identified as important in CG best practice codes in Australia and internationally (ASX CG Code 2003 and 2007; USA Blue Ribbon Committee Report, 1999; the OECD Report, 2001; The UK Corporate Governance Code, 2010).

Companies are ranked annually from 1 to 250 , where 1 is the best ranked firm, according to their overall CG standing relative to other companies reported on that year. To convert the Horwath rank to one that is increasing in $\mathrm{CG}$, we reverse the ranking given in the original report, adjust for ties, and transform the reversed rankings to range between 0 and 100, where 100 denotes the 'best' CG, as in BB06. In preliminary analysis and in sensitivity tests we also measure CG by the number of stars awarded in the Horwath report. The star rating system awards 5 stars for "outstanding” CG structures, 4.5 stars when CG was excellent "except in a few minor areas", 4 stars when CG structures were "very good" and the firm "met the ${ }^{10}$ The 2003 issue excluded six firms due to missing data. 
majority of best practice standards", 3.5 stars when CG structures were "generally good" and the firm met "most of best practice standards", 3 stars when CG structures were "adequate" and met "some of best practice standards", 2 stars when CG structures were "lacking in some key areas" and 1 star for very poor CG (WHK Horwath, 2008, p. 33).

The full details of the Horwath rating system are proprietary and we are unable to comment on the assignment of stars or rankings beyond the information provided in the reports themselves. We note that our reverse ranking procedure is re-based each year, making it less susceptible to secular change, whereas the star ranking is not re-based (i.e. it is an absolute measure) and demonstrates an improvement in CG practices over our study period.

\subsection{Other data sources}

To maximise sample coverage, we use the Aspect Financial Database of Australian listed companies' financial statement data, which are 'as reported'. We extract data for total assets, long-term debt, industrial sector and the date of the announcement of the company's annual results from this source. Other sources we consulted, to determine more accurately the date on which a company's Preliminary Final Statement/Report (PFS) was first announced to the market, include the ASX, Bloomberg, Compustat Global, Institutional Brokers' Estimate System ( $/ \mathrm{B} / \mathrm{E} / \mathrm{S})$, Reuters and Worldscope. Where there is a conflict in the dates from these seven sources, we use the earliest plausible date. ${ }^{11}$ Data for the number of documents lodged with the ASX and their release dates are sourced from the ASX via the Securities Industry Research Centre of Asia-Pacific (SIRCA). We use all documents released to the ASX as our measure of the frequency of disclosure, but also include measures confined to disclosures classified by the ASX as ex ante price sensitive. ${ }^{12}$ Daily share prices and returns are sourced

\footnotetext{
${ }^{11}$ We require the release date to be greater than 14 days but less than 180 days from the financial year end date to help ensure data integrity.

${ }^{12}$ Examples of disclosures by companies to the ASX are information regarding takeovers, security holdings, periodic reports, quarterly earnings or cash flow reports, capital changes, asset acquisitions or disposals and
} 
from SIRCA's Daily Database. We use the Australian All-Ordinaries Accumulation Index to measure the return on the whole market. We match the financial data to the $\mathrm{CG}$ ratings in the following year's Horwath report (i.e. 2001 calendar year financial data are matched to CG ratings in the 2002 Horwath report). Merging the data collected from the various sources yields a final dataset of 1,487 observations on 417 unique firms with financial years ending in 2001 to $2008 .^{13}$

\section{Research Method}

\subsection{Abnormal Performance Indexes (APIs)}

Firms that underperformed the market over the 365 day period are classified as 'Bad News' firms for that year, while those that equalled or outperformed the market are 'Good News' firms. Since our calculations are mostly based on continuously compounded (log) returns, when pooling Good and Bad news cases the cumulative market-adjusted price relative (Cumprel) for a Bad News case was transformed (into Cumprel_adj) as follows: Cumprel_adj $=\exp (-\log ($ Cumprel $))$, where exp denotes the exponential function and log the natural log function. In terms of CG, we designate firms with a $1 \operatorname{star}(N=64$ firm-years) or 2 star $(N=258) C G$ rating as 'Worst $C G$ ' as these firms are lacking $C G$ in key areas or had very poor CG under the Horwath rating scheme. Firms with a 5 star rating are designated as 'Best CG' ( $N=168$ firm-years). In the spirit of Ball and Brown (1968), six 'portfolios' are then constructed: (Best/Worst CG) x (Good/Bad/All News). All stocks in a category of interest (e.g., cases of Bad news where the firm was also rated in 2008 among those with the best CG) were then included in 2008 in the 'portfolio' for that category.

dividend announcements. Whether a particular disclosure is ex ante deemed price sensitive is determined by the ASX prior to the document's release to the market. For a detailed discussion of the ASX's announcement process see Brown et al. (2005; reproduced in Brown, 2013b).

${ }^{13}$ The number of observations per year is as follows: 166, 178, 184, 184, 187, 191, 194 and 203 in 2001 to 2008 respectively. 
Daily averages for each portfolio are calculated by dividing the sum of the members' cumulative market-adjusted price relatives on that day by the number of cases in the portfolio; the time-series of the portfolio daily averages is then re-scaled to an initial value of zero at the end of day -365 and a terminal value of 1 at the end of day zero. We adopt the Ball and Brown (1968) methodology to plot the APIs and examine the plots to determine the timeliness of good versus bad news across CG partitions. ${ }^{14}$

\subsection{Multivariate relationships}

\subsubsection{BB06 replication}

Initially we replicate the document count and timeliness of price discovery models in BB06, as in Eq. (1), which is estimated using pooled Ordinary Least Squares (OLS) methods:

$$
\operatorname{DepVar}_{i t}=\beta_{0}+\beta_{1} C_{i t}+\beta_{2} \text { Goodnews }_{i t}+\beta_{3} \text { Size }_{i t}+\beta_{4} \text { Report }_{i t}+\lambda_{t}
$$

where DepVar is a measure of document count or timeliness of price discovery (detailed below), CG is a measure of CG as described in section 3.1, Goodnews is an indicator variable which takes the value of one when the firm's share price outperforms the market over the year and zero otherwise, Size is measured by the natural log of market capitalisation at the end of the financial year, Report is an indicator variable which takes the value of one when the firm was required to lodge a Quarterly Report with the ASX during the year, ${ }^{15}$ and $\lambda$ is a vector of indicator variables that identify the particular year.

\footnotetext{
${ }^{14}$ Since the ratings relate to financial years ending the year before (i.e., 2001 to 2008), abnormal performance indexes (APIs) were calculated over the same 365 days as the timeliness of prices is measured for financial years ending in 2001 to 2008. For example, for a company included in the 2008 Horwath report that ended its 2007 financial year on 30 June and on Wednesday 15 August 2007 filed with the ASX a PFS containing its 2007 results, the market-adjusted, buy-and-hold API would be calculated from the daily returns over 365 calendar days ending 29 August 2007, which is the announcement date plus 14 days to allow price to settle. See below for further explanation; also Ball and Brown (2014).

${ }^{15}$ During our sample period the ASX adopted the GICS classification scheme, which does not map exactly into the ASX industry groupings available to BB06.
} 
To obtain the document count measures, we count the number of disclosure documents released by the firm at any time over 365 days ending with the day of the PFS, denoted day 0 in the documents analysis. ${ }^{16}$ Each document released by the firm is counted, irrespective of whether another document was also released that day. The dependent variable is the log of the document count (either the total of all documents, or only those that are classified by the ASX as ex ante price sensitive).

To measure the timeliness of price discovery, we adapt the BB06 metric to calendar time. BB06 used 250 trading days, which is about a year in calendar time. We adopt a 365-day calendar year and calculate the measure in calendar time to accommodate future international comparisons. The price series is forward-filled (price is brought forward from the previous day if the stock is not traded that day). This metric traces the share price over 365 calendar days ending 14 days after the firm's annual PFS announcement, which is the primary statement of the year's financial results. Specifically:

$$
\text { Timeliness }(\text { Prices })=\left(\left(\sum_{t=-365}^{t=-1}\left|\log \left(P_{0}\right)-\log \left(P_{t}\right)\right|\right)-0.5\right) / 365
$$

where $P_{t}$ is the daily market-adjusted share price and the constant $-0.5 / 365$ is an adjustment to recognise the flow of information is reflected in returns over the day. ${ }^{17}$

The timeliness measure captures the speed of information discovery in a firm's share price (i.e. the level of market transparency regarding the firm's activities) and makes no assumption about the mechanism of price discovery. Specifically, it measures how quickly the share price reaches the day 0 price (the terminal value in the time series). If a firm releases value-relevant information on a more timely basis and in turn the information is

\footnotetext{
${ }^{16}$ We use the annual PFS release date as day 0 in the analysis of documents because we know the precise date. When analysing prices we re-define day 0 as the release date +14 days to allow them to "settle". BB06 used 10 trading days after the firm's annual PFS announcement, which is comparable to 14 calendar days in our study.

${ }^{17}$ If daily log returns were i.i.d. (independently and identically distributed), Timeliness would have an expected value of 0.5 .
} 
incorporated into share price quickly, then the metric will have a value closer to zero; i.e. timeliness of price discovery takes a smaller value when information is integrated more quickly. We also use a calendar year version of BB06's Timeliness Deflated measure, which adjusts for the magnitude of the drift in price. This measure is calculated by deflating the raw timeliness measure in Eq. (2) by one plus the absolute value of the market-adjusted rate of return on the share over the period used to calculate timeliness.

Eq. (1) includes a control for good news because firms with superior performance have been found to release more documents (Lev and Penman, 1990). In addition, as already noted they may prefer to release this information in a timelier fashion. We control for larger firms as they are subject to greater scrutiny, and have stronger incentives to keep analysts and institutional investors informed, thereby reducing information asymmetry and possibly mitigating political costs (Dye, 2001; Lang and Lundholm, 1993). Thus we expect firm size to be positively associated with disclosure frequency and the timeliness of prices to be faster for larger firms (Beekes and Brown, 2006, 2007).

\subsubsection{Building on BB06}

We build on the model in Eq. (1) by introducing new dependent variables, by including explanatory variables designed to capture the effect of the ASX CG Code and legislative changes referred to in section 2.6, and by adding control variables for leverage, industry and year, as in Eq. (3):

$$
\begin{aligned}
& \text { DepVar }_{i t}=\beta_{0}+\beta_{1} \text { CG }_{i t}+\beta_{2} \text { Goodnews }_{i t}+\beta_{3} \text { Size }_{i t}+\beta_{4} \text { Volatility }_{i t} \\
& +\beta_{5} \text { Leverage }_{i t}+\beta_{6} \text { ASX }_{i t}+\beta_{7} \text { ASX } \cdot C G_{i t}+\beta_{8} C L E R P_{i t}+\beta_{9} C L E R P \cdot C G_{i t} \\
& +\delta_{i t}+\lambda_{t}
\end{aligned}
$$

where DepVar is the document and timeliness dependent variables (the new variables are detailed below); Volatility is measured by the standard deviation of daily stock returns over 
the 90 days before the start of the estimation period; Leverage is measured by the firm's financial year-end ratio of long-term debt to total assets; $A S X$ is an indicator variable equal to one for years following the introduction of the ASX CG Code (i.e. years 2003-2008) and 0 otherwise; CLERP is an indicator variable equal to one for years following the enactment of CLERP 9 (i.e. years 2005-2008); and $\delta$ is a vector of industry indicator variables. Other variables are previously defined. For the timeliness of prices models we include an interaction term between Goodnews and CG to capture differential timeliness according to the favourability of the news.

The interpretation of the coefficients of interest in Eq. (3) is as follows. $\beta_{1}$ is the effect of better CG on the dependent variable before the ASX CG Code was introduced (for the purpose of the present discussion, a better governed firm is one with a CG rank that is one standard deviation above the mean). $\beta_{6}$ is the marginal effect of the code for a firm with average $\mathrm{CG}$, while $\beta_{7}$ is the additional effect for a firm with better CG. $\beta_{8}$ and $\beta_{9}$ are the corresponding estimates for CLERP 9. Hence the combined effect of both the Code and CLERP 9 on a firm with better $\mathrm{CG}$ is $\beta_{6}+\beta_{7}+\beta_{8}+\beta_{9}$ while their effect on one with average $\mathrm{CG}$ is $\beta_{6}+\beta_{8}$.

BB06's two document count variables pay no regard to the timing of the documents' release, while the two BB06 timeliness of prices variables suffer from volatility-induced bias, by construction. We address these deficiencies by adding two dependent variables that reflect the timeliness of document disclosures and three timeliness of prices metrics that are adaptations of metrics discussed in Beekes and Brown (2007), namely the timeliness of good, of bad, and of all news.

To measure the timeliness of all documents, the number of documents released each day is cumulated in a daily time series and the timeliness metric is calculated as in Eq. (4). The 
procedure is repeated for price sensitive documents. Smaller values are associated with earlier (more timely) announcements to the share market.

$$
\text { Timeliness }(\text { Docs })=\left(\sum_{t=-365}^{t=-1}\left(C D_{0}-C D_{t}\right) / C D_{0}-0.5\right) / 365
$$

Constructing the three additional metrics for the timeliness of prices is more complicated. To measure the timeliness of good news, we first identify the third quartile of the stock's raw (unadjusted) daily log returns, $r_{t}$, that are positive; call the third quartile value $Q_{3}$. We then create a market-adjusted daily $\log$ return series, $\left(r_{t}^{*}, t=s, \ldots, 0\right)$, where $s$ is the starting day of the series (when timeliness is calculated from returns, $s=-364$ for the annual timeliness measure and ends on day $t=0$, as described earlier). Next we construct a time series of cumulative good news returns, $C_{t}^{G}$, by setting $C_{-365}^{G}=0$ and cumulating the daily marketadjusted $\log$ return series $C_{t}^{G}=C_{t-1}^{G}+r_{t}^{G}$ from day -364 to day 0 , where $r_{t}^{G}=r_{t}^{*}$ if $r_{t}>Q_{3}$; otherwise $r_{t}^{G}=0$. The timeliness of good news is then calculated as in Eq. (5), which corresponds to Eq. (2) and Eq. (4):

$$
\text { Timeliness }(\text { Good News })=\left(\sum_{t=-365}^{t=-1}\left(C_{0}^{G}-C_{t}^{G}\right) / C_{0}^{G}-0.5\right) / 365
$$

The raw (unadjusted) returns are filtered at the third quartile to mitigate undue noise. The ASX trades securities about 250 days of the year, so roughly a third of the prices are forwardfilled before we take non-trading into account. To suppress noise from bid-ask bounce and the like, we chose the third quartile as the filter, based on inspection of the empirical distributions of log returns for firm-years in the sample. The equivalent procedure is adopted for bad news. The all news measure is the weighted sum of the good and bad news measures, 
where the weights sum to one and are $\left(C_{0}^{G} /\left[C_{0}^{G}+C_{0}^{B}\right]\right)$ and $\left(C_{0}^{B} /\left[C_{0}^{G}+C_{0}^{B}\right]\right)$ respectively and $C_{t}^{G}$ and $C_{t}^{B}$ are the unsigned good and bad news cumulative values at the end of day $0 .{ }^{18}$

Our models include controls for leverage and volatility, which could impact on the level of firm disclosure. Leverage proxies for the degree of risk associated with default on debt. Creditors and lenders can request additional information on a timelier basis to monitor their investment more closely as leverage rises. Also, firms that are more highly levered may release more information to shareholders, who face greater risk (Taylor, Richardson, Tower and Hancock, 2012). Thus more highly levered firms may release more documents, be more timely in their releases, and be subject to more efficient stock price discovery. Similarly, a firm with greater volatility in performance may release additional information, although as BB06 point out their measures of the timeliness of price discovery can be detrimentally affected by a more volatile stock price. Our regression analysis controls for industry and, in sensitivity analysis, we assess the robustness of the results to the exclusion of three industry sectors that may have incentives to disclose information different from other sectors (specifically, the energy, utilities and finance sectors). We use the same controls in all models (Good News, Size, Leverage, and Volatility) except for the Timeliness of Good and Bad News models, which exclude the Good News control. ${ }^{19}$

We expect the coefficient on CG Rank to have a positive sign in the document count models given the predicted positive association between CG and the frequency of disclosure. In all of the timeliness models (for prices and documents), CG Rank is expected to have a negative sign since better governed firms are predicted to be more timely when releasing information and to exhibit greater transparency.

\footnotetext{
${ }^{18}$ See Beekes and Brown (2007) for further discussion of unfiltered versions of the good, bad and all news timeliness measures.

${ }^{19}$ We wish to keep our principal models relatively parsimonious to enable comparisons with the results of Beekes and Brown (2006). In sensitivity analysis we re-specify models to include measures of share ownership and growth, in order to explore alternative explanations for the principal results.
} 
We fit the models using pooled OLS rather than adopting a firm fixed effects approach because the CG measures exhibit considerable inertia or 'stickiness' (Hermalin and Weisbach, 2012; Black, Jang and Kim, 2006; Brown, Beekes and Verhoeven, 2011). Stickiness is manifest in our sample in that the variance in CG Rank between firms is 26.52, while the within-firm variance is 13.28. For CG Stars the variance between firms is 1.04 and the within-firm variance is 0.53 [details are not tabulated]. All models are estimated with standard errors clustered by firm to control for heteroskedasticity and within-firm correlation in the residuals. We address concerns regarding endogeneity in section 5.4.

\section{Results}

\subsection{Descriptive statistics}

-Table 1-

Panel A of Table 1 shows the descriptive statistics for the variables over the whole period and their means before and after the ASX CG Code took effect. Firms' CG is rated 3.5 stars on average (CG Stars). Some firms were assessed as having very poor CG (awarded 1 star) while others were considered exemplary (awarded 5 stars). Firms in the sample released 93 documents per year on average during the eight year period (All Documents), although the standard deviation is 71 indicating some firms released considerably more documents than the average. About a third of all documents released are classified by the ASX, ex ante, as price sensitive (PS Documents).

Recall that smaller values of timeliness indicate more timely outcomes. The timeliness of all (price sensitive) documents ranges between $0.16(0.13)$ and $0.77(0.90)$, with a mean of 0.46 (0.51). The BB06 timeliness metrics, Timeliness (Timeliness deflated) of prices, range between $0.04(0.03)$ and $0.73(0.38)$ with a mean of $0.20(0.14)$, after winsorising. The timeliness of good news and the timeliness of bad news have similar distributions with both having sample means of 0.51 . 
Since the ASX CG Code was introduced there has been a statistically greater level of document disclosure, as reflected in the average number of documents released annually as well as the number of documents classified by the ASX as price sensitive, and more timely price discovery when the raw timeliness metric is used but no significant change for deflated timeliness, which partially controls for volatility. The timeliness of good and bad news has declined since the ASX CG Code took effect (the metrics are larger), but the timeliness of price sensitive documents has increased. Also the mean star rating of firms' CG has risen.

Panel B of Table 1 shows the distribution of the sample by sector using Global Industry Classification Standard (GICS) definitions. Some 24 per cent of observations are from the Materials sector, 19 per cent from Consumer Discretionary and 18 per cent from the Industrial sector. The remaining sectors (Consumer Staples, Energy, Financials, Healthcare, Information Technology, Telecommunication Services and Utilities) each comprise 10 per cent or less of the sample. CG star ratings are largest on average in the Financials sector. The mean number of documents shows considerable variation in the frequency of releases by industry, with the greatest number being in the energy sector.

Table 2 shows the product-moment correlations. The two CG variables, CG Rank and CG Stars, are positively correlated by construction $(r=0.947)$. In general CG (whether measured by CG Rank or CG Stars) is positively correlated with the number of company announcements made via the ASX (Log Docs and Log PS Docs). CG is positively correlated with firm size and leverage, but negatively with volatility. On the whole the bivariate correlations indicate firms whose CG is rated more highly do make more frequent and more balanced disclosures, and that the disclosures are more timely.

-Table 2-

\subsection{Graphical analysis}


As discussed, we adopt Ball and Brown's (1968) API methodology to show the relationship, at the portfolio level, between the speed of price discovery over the course of the year and the quality of the firm's CG. To illustrate, if better governed firms are more forthcoming in their disclosures, then when graphed the API of the Best CG-All news portfolio should tend to be above the API of the Worst CG-All news portfolio.

Many comparisons are possible so we restrict our analysis to an annual timeliness statistic for five fundamental comparisons: (1) All news, Best vs. Worst CG; (2) Good news, Best vs. Worst CG; (3) Bad news, Best vs. Worst CG; (4) Good news vs. Bad news, Worst CG; and (5) Good news vs. Bad news, Best CG. The APIs for these five comparisons are presented in Figures 1 to 5 . In the third and fourth comparisons the apparent differences are statistically reliable in that the size of the difference in the timeliness of the pair of portfolios in each figure is unlikely to have been observed by chance. ${ }^{20}$ In the case of the first, second and fifth comparisons, we do not rule out the possibility that the differences in the portfolios' timeliness statistic are due to chance.

- Figures $1-5$ -

It appears from this analysis that, prima facie, better governed firms are on the whole priced more efficiently (i.e., news is priced earlier) in equity markets than poorer governed firms (Figure 1), consistent with H2, although good news is priced more efficiently for poorer governed firms (Figure 2), consistent with H3. Correspondingly, bad news is priced more efficiently for better governed firms (Figure 3), consistent with H4. Consistent with H5 there is striking evidence that the timeliness of good news relative to bad is associated with CG: in Figure 4 the API for good news is everywhere above that for bad news for the worst

\footnotetext{
${ }^{20}$ We use a re-sampling procedure to decide whether the observed differences may be due to chance. The relative frequency $(r f)$ with which resampling trials support each predicted difference in the portfolios' timeliness statistic is as follows: (1) $r f>0.81$ (n.s.); (2) $r f>0.75$ (n.s.); (3) $r f>0.998$; (4) $r f>0.982$; (5) $r f>0.628$ (n.s.). Further details on the procedure are in the appendix.
} 
governed firms, other than in the immediate region of the end points which coincide by construction, whereas a completely different picture is apparent in Figure 5 for the better governed firms. For them, it appears that in the first few months of the year good news may be priced earlier than bad news, but over the last few months bad news is priced substantially earlier than good news - to the point where the timeliness metric averaged over the whole year indicates bad news is priced on average more efficiently.

Bearing in mind that Australian listed companies must file a half-yearly as well as an annual report with the stock exchange, the behaviour of the APIs in Figures 3-5 in the region of event day -180 points to the half-yearly report being a significant market update, perhaps more so for bad news. We note that, for the sub-set of 1,340 cases where we could source the release date of the firm's half-yearly report, the median number of days between the halfyearly and yearly announcements was 182 days, while in more than $90 \%$ of the 1,340 cases the PFS was released between 173 and 202 days after an earlier half-yearly report (corresponding to days -187 and -216 in the graphs). The dotted vertical lines in Figures 1-5 indicate the approximate Half-Yearly and PFS announcement periods, the latter being from three days before to three days after the reported release date in order to allow for the absence of trading in calendar time (due e.g. to public holidays or weekends).

We conclude that, on the whole, the proposition that $C G$ is associated with market transparency is supported, although even the best governed firms are not exactly even-handed in their disclosure of good and bad news. However, as strong as some of the results in this section appear to be, we have not yet controlled for other factors that, according to Table 2, are correlated with $\mathrm{CG}$ and may be driving some of these results. In the remaining sections we conduct more detailed tests that are designed to deal with this possibility.

\subsection{Multivariate analysis, primary results}


The results in this section are from pooled OLS estimation with standard errors clustered by firm to control for heteroskedasticity and within-firm correlation in the residuals. All coefficients displayed in Tables 3 and 4 relate to variables that have been standardized to assist interpretation. $^{21}$

\subsubsection{Documents}

First we examine the relationship between CG and document disclosures. We begin by replicating BB06 with our extended dataset (results are shown in columns 1 and 2 of Table 3). Under H1, we would expect better CG to be associated with greater document disclosure (positive coefficient on CG). The results are consistent with this prediction. As mentioned in section 4.2.2 we expand the BB06 models, the results of which are reported in columns 3 to 6 of Table 3. To assess the impact of additional explanatory variables, we report nested $F$-tests from regressions which sequentially add blocks of variables to the regression model (shown at the bottom of Table 3). The base case (Block 1) includes CG Rank, Good News, Size, Volatility, Leverage and industry controls. Block 2 includes variables relating to the ASX CG Code (ASX and $A S X \cdot C G$ Rank), and Block 3 includes variables relating to CLERP (CLERP and CLERP.CG Rank). Inclusion of the additional variables relating to the ASX CG Code is statistically significant in both document count models (columns 3 and 4) and in the timeliness of price sensitive documents model (column 6), but the variables relating to CLERP 9 are significant only in the timeliness of price sensitive documents model.

-Table 3-

Table 3 shows firms with better CG are associated with a greater number of disclosure documents (i.e. CG Rank has a positive coefficient in columns 3 and 4) prior to the ASX CG

\footnotetext{
${ }^{21}$ The standardization procedure is as follows. Continuous variables are transformed by subtracting the mean and dividing by the standard deviation; and indicator variables are transformed by subtracting the mean. For interacted terms, we subtract the mean of the variable created by the interaction of the indicator variable and the standardized continuous variable. The transformations are based on the means and standard deviations of the cases used to fit the particular model.
} 
changes, which is consistent with results reported by BB06. Following the ASX CG changes, all firms tended to release more documents than in prior years (ASX coefficient $=0.376$ in the all documents model and 0.753 in the price sensitive documents model). However, the increase was greater among poorer governed firms (the coefficient on the interaction between ASX and CG Rank is -0.111 for all documents and -0.093 for PS documents), which indicates a levelling in disclosure practices across firms following the emphasis on greater transparency in the ASX CG Code. The passage of CLERP 9 was followed by little change in the frequency of all document disclosures across the whole range of CG, whereas there is some evidence that the number of price sensitive disclosures declined marginally among better governed firms. ${ }^{22}$

We find no significant effect of $\mathrm{CG}$ on the timeliness of all or ex ante price sensitive documents prior to the ASX CG changes (columns 5 and 6). However, we note a weak effect showing tardier disclosures of price sensitive documents lodged by better governed firms after the ASX CG Code took effect (ASX.CG Rank is positive and significant), which is inconsistent with H6. We also find CLERP 9 was followed by more timely releases of price sensitive documents by firms regardless of their governance ranking.

In summary, although better governed firms released more documents to the ASX prior to the ASX CG Code, their disclosures were not significantly more timely. Following the ASX CG Code, the average firm released more documents overall as well as more price sensitive documents. There is evidence that better governed firms released marginally fewer documents (both in terms of the number of price sensitive documents as well as all documents) and there is some evidence that better governed firms took longer to release price

\footnotetext{
${ }^{22}$ The coefficient on the interaction between CLERP and CG Rank of -0.033 in column 4 implies that a firm with a CG Rank two standard deviations above the sample mean is predicted to release one fewer price sensitive document annually since the passage of CLERP 9 . This prediction is calculated as exp(-0.033*2*0.849), where $\exp ()$ is the exponential function and 0.849 is the standard deviation of the log of the number of ex ante price sensitive documents (see Table 1).
} 
sensitive information relative to earlier years. It also appears that firms have been releasing price sensitive documents sooner since the passage of CLERP 9.

\subsubsection{Timeliness of prices}

Under H2 we would expect to find faster price discovery for better governed firms (a negative coefficient on CG). Replicating the results in BB06 yields estimates consistent with this prediction (columns 1 and 2 of Table 4). The results from our expanded BB06 models are reported in columns 3 and 4 and additional dependent variables to examine the timeliness of good, bad and all news are reported in columns 5, 6 and 7. The nested F-tests reported at the bottom of Table 4 show the ASX and CLERP 9 variables are significant in the timeliness of good, bad and all news models, but not in the expanded BB06 models.

\section{-Table 4-}

Our expanded BB06 models (columns 3 and 4) yield no statistically significant relationship between CG and timeliness or timeliness deflated either before or after the ASX CG changes or CLERP 9, which is inconsistent with $\mathrm{H} 2$ and the reduced forms in BB06 (see the results in columns 1 and 2). This result may be due to bias in the BB06 timeliness measures caused by individual stock volatility, a finding echoing some earlier work on the effect of corporate disclosure and transparency on price and return behaviour. Bushee and Noe (2000) for example report high levels of disclosure attract transient institutional investors who trade aggressively on short-term earnings news, thus increasing return volatility. Botosan and Plumlee (2002) find more timely disclosure from quarterly reports is positively related to the cost of equity capital, which on the surface seems counter-intuitive. They attribute the relationship to short-termism among investors resulting in greater volatility of share prices being associated with more frequent disclosures. Given the half-yearly reporting requirement in Australia and the mid-year updates in price observed in Figures 1-5, we are not able to rule 
out the possibility that opportunistic investing adds to volatility and confounds the relationship between $\mathrm{CG}$ and the BB06 measures of the timeliness of price discovery.

The timeliness measures in columns 5, 6 and 7 do not suffer from the same volatility-induced bias and should yield more reliable estimates. For the period before the ASX CG Code, firms with better CG appear to be more timely in the recognition of all news (negative coefficient on CG Rank in column 5). The positive coefficient on the interaction between good news and CG suggests better governed firms place less emphasis on the early release of good news (column 5), consistent with H3. Good news (column 6) is less timely following the ASX CG Code for weaker governed firms (coefficient on $A S X=0.218$ ) and the more so for better governed firms (coefficient on $A S X \cdot C G$ Rank $=0.152$ ). Relative to weaker governed firms, better governed firms are less timely when there is good news (the sum of the coefficients on CG Rank and $A S X \cdot C G$ Rank is 0.062 ), consistent with H3. This result again indicates a more balanced approach to good news recognition since the code was introduced. Although the timeliness of bad news (column 7) is improved for weaker governed firms after the ASX CG Code (coefficient on ASX $=-0.323$ ), we find no reliable evidence of an incremental effect of better CG on the timeliness of bad news, which is inconsistent with $\mathrm{H} 4$ and the API analysis. It may be evidence of an inherently conservative tendency of all firms to get bad news out to the market on a timely basis, as suggested by Skinner (1994). Curiously, CLERP 9 has been followed by less efficient pricing of all news, whether good or bad and independently of the firm's governance rating (the coefficient on CLERP is significantly positive in columns 5,6 and 7 but its interaction with CG Rank is smaller in size and not statistically significant).

In summary, better governed firms experience more timely price discovery and they are more balanced in recognition of good and bad news. After the ASX CG Code, the timeliness of good news has slowed relative to that of bad news for firms of all CG 'types', while better governed firms may have become more cautious in recognising good news. Furthermore, in 
that period the timeliness of bad news appears not to have been related to differences in CG. Since the passage of CLERP 9, the average firm has been taking a more cautious approach to news recognition, which on balance has led to slower integration of news into prices. Interestingly, we find no significant incremental effect of CLERP 9 for better governed firms.

\subsection{Robustness}

Our results are robust to a range of alternative specifications and variable definitions. They include: (i) winsorising all continuous variables at the top and bottom 2.5 per cent of the distribution, to limit the influence of outliers; (ii) using the natural log of total assets as an alternative measure of Size; (iii) using CG Stars instead of CG Rank; (iv) excluding the energy sector $(N=150)$; (v) excluding the financials and utilities sectors $(N=68$ and $N=38$ respectively); (vi) including the percentage shareholding of the largest 20 shareholders, sourced from Aspect Financial; ${ }^{23}$ (vii) including growth opportunities, proxied by the market value of shareholders' equity divided by its book value, ${ }^{24}$ (viii) using the raw document count for total documents and ex ante price sensitive documents and fitting the document count models by Poisson methods; and (ix) excluding cases for 2008, to preclude the possibility that data from the global financial crisis period drive our results.

We also use a measure of 'abnormal' documents, calculated as the number of documents a firm releases during the year less the mean number of documents released by companies with the same GICS code as the firm in that particular year. Results confirm that, prior to the ASX CG Code, CG was positively associated with document disclosure frequency (price sensitive

\footnotetext{
${ }^{23}$ Greater ownership by the largest 20 shareholders may result in a lower perceived need to disclose information. We find firms with more concentrated ownership issue fewer documents (all and price sensitive), but experience more timely price discovery (timeliness and timeliness deflated). This variable is not significant in any other model.

${ }^{24}$ We include Growth to capture firms' desire to retain information for proprietary reasons. The coefficient on Growth is negative and statistically significant in the document count models, consistent with the view that firms with high growth prospects release less information. Growth is negative in the timeliness of good news, but positive in the timeliness of bad news models, suggesting good news about firms with more growth opportunities is priced earlier but bad news is not. Growth is not significant in other models.
} 
and all documents). However, the interaction terms between CG Rank and ASX and CLERP are insignificant.

To examine the potential influence of endogeneity in $\mathrm{CG}$, we explored the use of instrumental variables (IV) estimation. Implementation of IV is far from straight forward as it requires the selection of instrumental variables that are both highly correlated with the variable for which they are instruments while at the same time being uncorrelated with the error (Kennedy, 2003, p.159; Larcker and Rusticus, 2007). We investigated the effect of using the average industrial sector level of CG and the average year level of CG (the current firm is excluded from the calculation of both instruments), and interactions of these variables with ASX.CG Rank and CLERP.CG Rank as instruments; however, the Hansen test indicates these instruments are not robust and yield unreliable IV results. When the instruments are not robust, Larcker and Rusticus $(2010 ; 187)$ argue "it is likely that IV estimates are more biased and more likely to provide the wrong statistical inference than simple OLS estimates that make no correction for endogeneity." For this reason we rely principally on pooled OLS results. $^{25}$

\section{Conclusions}

We re-examine the link between CG and disclosure frequency, the timeliness of disclosures, and the timeliness of information discovery reflected in share prices for a sample of Australian listed firms with financial years ending between 1 January 2001 and 31 December 2008. In preliminary analysis, we use the Ball and Brown (1968) API methodology to graph the relationship, at the portfolio level, between the speed of price discovery over the course of a year and the quality of the firm's CG. We tentatively conclude from this analysis that better

\footnotetext{
${ }^{25}$ We did investigate the sensitivity of our results to the time period of $C G$ in another attempt to address this issue, using OLS methods. Rather than estimating the models with contemporaneous disclosure proxies and CG plus control variables as in Tables 3 and 4, we used the next period's values of the dependent variables (i.e. year $t+1$ ) and the current period's CG and control variables (i.e. year $t$ ). The results were comparable with those already reported, although the statistical significance of interaction terms with CG can be sensitive to this specification.
} 
governed firms are on the whole priced more efficiently (i.e., news is priced earlier) in equity markets than poorer governed firms, although good news is priced earlier for poorer governed firms. Correspondingly, bad news is priced earlier for better governed firms.

We then take advantage of additional data now available to shed new light on the results reported by Beekes and Brown (2006). By exploiting a time series of governance data collected in a consistent fashion over an extended time period, we find the introduction of the ASX CG Code was accompanied by increased disclosure for all firms, together with increased timeliness in the share market pricing of bad news relative to good news, suggesting a levelling of practice as firms with weaker CG became more transparent. Since CLERP 9 firms appear to have become more cautious in their disclosure policies and there has been a reduction in the timeliness with which both good and bad news are priced. Our results also indicate legislative change has brought about a more level playing field for corporate disclosures. However, while it is now more difficult for better governed firms to distinguish themselves through their disclosure policies, there may still be enough room for them to signal their quality that way. 


\section{References:}

Ahmed, K., and D. Henry, 2012, Accounting conservatism and voluntary corporate governance mechanisms by Australian firms, Accounting and Finance 52(3), 631662.

Akerlof, G.A., 1970, The market for "lemons": Quality uncertainty and the market mechanism, The Quarterly Journal of Economics 84(3), 488-500.

Australian Securities and Investments Commission, 2011a, 11-26MR Decision in Fortescue Metals Group appeal. Available at:

http://www.asic.gov.au/asic/asic.nsf/byheadline/1126MR+Decision+in+Fortescue+Metals+Group+appeal.

Australian Securities and Investments Commission, 2011b, 11-125MR Decision in Centro civil penalty case. Available at: http://www.asic.gov.au/asic/asic.nsf/byHeadline/11125MR $\% 20$ Decision $\% 20$ in $\% 20$ Centro\%20civil\%20penalty $\% 20$ case?opendocument.

Australian Securities and Investments Commission, 2012, 12-275MR Decision in James Hardie penalty proceedings. Available at:

http://www.asic.gov.au/asic/asic.nsf/byheadline/12-

275MR+Decision+in+James+Hardie + penalty+proceedings?openDocument.

Australian Stock Exchange Corporate Governance Council, 2003, The principles of good corporate governance and best practice recommendations (Australian Stock Exchange Ltd). Available at: http://www.asx.com.au/governance/corporategovernance.htm.

Australian Stock Exchange Corporate Governance Council, 2007, Corporate governance principles and recommendations. $2^{\text {nd }}$ Ed. (Australian Stock Exchange Ltd). Available at: http://www.asxgroup.com.au/corporate-governance-council.htm. 
Australian Stock Exchange, 2012, ASX Listing Rules, Guidance Notes and waivers. Chapter 3 Continuous Disclosure (Australian Stock Exchange Ltd). Available at:

http://www.asxgroup.com.au/asx-listing-rules-guidance-notes-and-waivers.htm.

Ball, R., and P. Brown, 1968, An empirical evaluation of accounting income numbers, Journal of Accounting Research 6(2), 159-178.

Ball, R., and P. Brown, 2014, Ball and Brown (1968): a retrospective, The Accounting Review 89(1), 1-26.

Bassett, M., P-S. Koh, and I. Tutticci, 2007, The association between employee stock option disclosures and corporate governance: Evidence from an enhanced disclosure regime, The British Accounting Review 39(4), 303-322.

Baum, C.F., M.E., Schaffer, and S. Stillman, 2010, ivreg2: Stata module for extended instrumental variables/2SLS, GMM and AC/HAC, LIML and k-class regression. Available at: http://ideas.repec.org/c/boc/bocode/s425401.html.

Beasley, M.S., 1996, An empirical analysis of the relation between the board of director composition and financial statement fraud, The Accounting Review 71(4), 443-465.

Beekes, W., and P. Brown, 2006, Do better-governed Australian firms make more informative disclosures? Journal of Business Finance and Accounting 33(3\&4), 422450.

Beekes, W., and P., Brown, 2007, On the timeliness of price discovery (Social Science Research Network). Available at: http://papers.ssrn.com/sol3/papers.cfm?abstract_id=938982.

Black, B.S., H. Jang, and W. Kim, 2006, Predicting firms' corporate governance choices: Evidence from Korea, Journal of Corporate Finance 12(3), 660-691.

Botosan, C.A., 1997, Disclosure level and the cost of equity capital, The Accounting Review 72(3), 323-349. 
Botosan, C.A., and M.A. Plumlee, 2002, A re-examination of disclosure level and the expected cost of equity capital, Journal of Accounting Research 40(1), 21-40.

Brown, P., 2013a, How can we do better? Accounting Horizons 27(4), 855-859.

Brown, P., 2013b, Financial Accounting and Equity Markets (Routledge, London and New York).

Brown, P., B. Howitt, and M. Wee, 2005, Order flow and price effects surrounding an ASX announcement, 2005 AFAANZ Conference Proceedings, Accounting and Finance Association of Australia and New Zealand (July), CD-ROM (reproduced in Brown 2013b).

Brown, P., S.L. Taylor, and T.S. Walter, 1999, The impact of statutory sanctions on the level and information content of voluntary corporate disclosure, Abacus 35(2), 138-162.

Brown, P., W. Beekes, and P. Verhoeven, 2011, Corporate governance, accounting and finance: A review, Accounting and Finance 51(1), 96-172.

Bushee, B.J., and C.F. Noe, 2000, Corporate disclosure practices, institutional investors, and stock return volatility, Journal of Accounting Research 38(Supplement), 171-202.

Clubb, C., 2006, Discussion of 'Do better-governed Australian firms make more informative disclosures?', Journal of Business Finance and Accounting 33(3\&4), 451-458.

Collett, P., and S. Hrasky, 2005, Voluntary disclosure of corporate governance practices by listed Australian companies, Corporate Governance: An International Review 13(2), 188-196.

Corporate Law Economic Reform Program (Audit Reform and Corporate Disclosure) Act, 2004. Available at:

http://www.comlaw.gov.au/Browse/Results/ByTitle/Acts/Current/Co/0.

Drienko, J., and S.J. Sault, 2013, The intraday impact of company responses to exchange queries, Journal of Banking and Finance 37(12), 4810-4819. 
Dye, R.A., 2001, An evaluation of 'Essays on Disclosure' and the disclosure literature in accounting, Journal of Accounting and Economics 32(1-3), 181-235.

Eng, L.L., and Y.T. Mak, 2003, Corporate governance and voluntary disclosure, Journal of Accounting and Public Policy 22(4), 325-345.

Fama, E., L. Fisher, M. Jensen, and R. Roll, 1969, The adjustment of stock prices to new information, International Economic Review 10(1), 1-21.

Gong, N., 2007, Effectiveness and market reaction to the stock exchange's inquiry in Australia, Journal of Business, Finance and Accounting 34(7 \& 8), 1141-1168.

Hamilton, K., 2004, The need for effective communication with market stakeholders, Australian Accounting Review 14(1), 3-8.

Hermalin, B.E., and M.S. Weisbach, 2012, Information disclosure and corporate governance, Journal of Finance 67(1), 195-233.

Kennedy, P., 2003, A Guide to Econometrics, $5^{\text {th }}$ Ed. (Blackwell Publishing, Oxford, UK).

Kent, P., and J. Stewart, 2008, Corporate governance and disclosures on the transition to International Financial Reporting Standards, Accounting and Finance 48(4), 649-671.

Kothari, S.P., S. Shu, and P.D. Wysocki, 2009, Do managers withhold bad news? Journal of Accounting Research 47(1), 241-276.

Lang, M., and R. Lundholm, 1993, Cross-sectional determinants of analyst ratings of corporate disclosures, Journal of Accounting Research 31(2), 246-271.

Larcker, D.F., and T.O. Rusticus, 2007, Endogeneity and empirical accounting research, European Accounting Review 16(1), 207-215.

Larcker, D.F., and T.O. Rusticus, 2010, On the use of instrumental variables in accounting research, Journal of Accounting and Economics 49(3), 186-205.

Lev, B., and S.H. Penman, 1990, Voluntary forecast disclosure, nondisclosure, and stock prices, Journal of Accounting and Research 28(1), 49-76. 
Lim, S., Z. Matolcsy, and D. Chow, 2007, The association between board composition and different types of voluntary disclosure, European Accounting Review 16(3), 555-583.

Matolcsy, Z., J. Tyler, and P. Wells, 2012, Is continuous disclosure associated with board independence? Australian Journal of Management 37(1), 99-124.

Nelson, J., G. Gallery, and M. Percy, 2010, Role of corporate governance in mitigating the selective disclosure of executive stock option information, Accounting and Finance $50(3), 685-717$.

Skinner, D.J., 1994, Why firms voluntarily disclose bad news, Journal of Accounting Research 32(1), 38-60.

Taylor, G., G. Richardson, G. Tower, and P. Hancock, 2012, The determinants of reserves disclosure in the extractive industries: evidence from Australian firms, Accounting and Finance 52 (Supplement), 373-402.

WHK Horwath, 2008, 2008 WHK Horwath corporate governance report (University of Newcastle). 


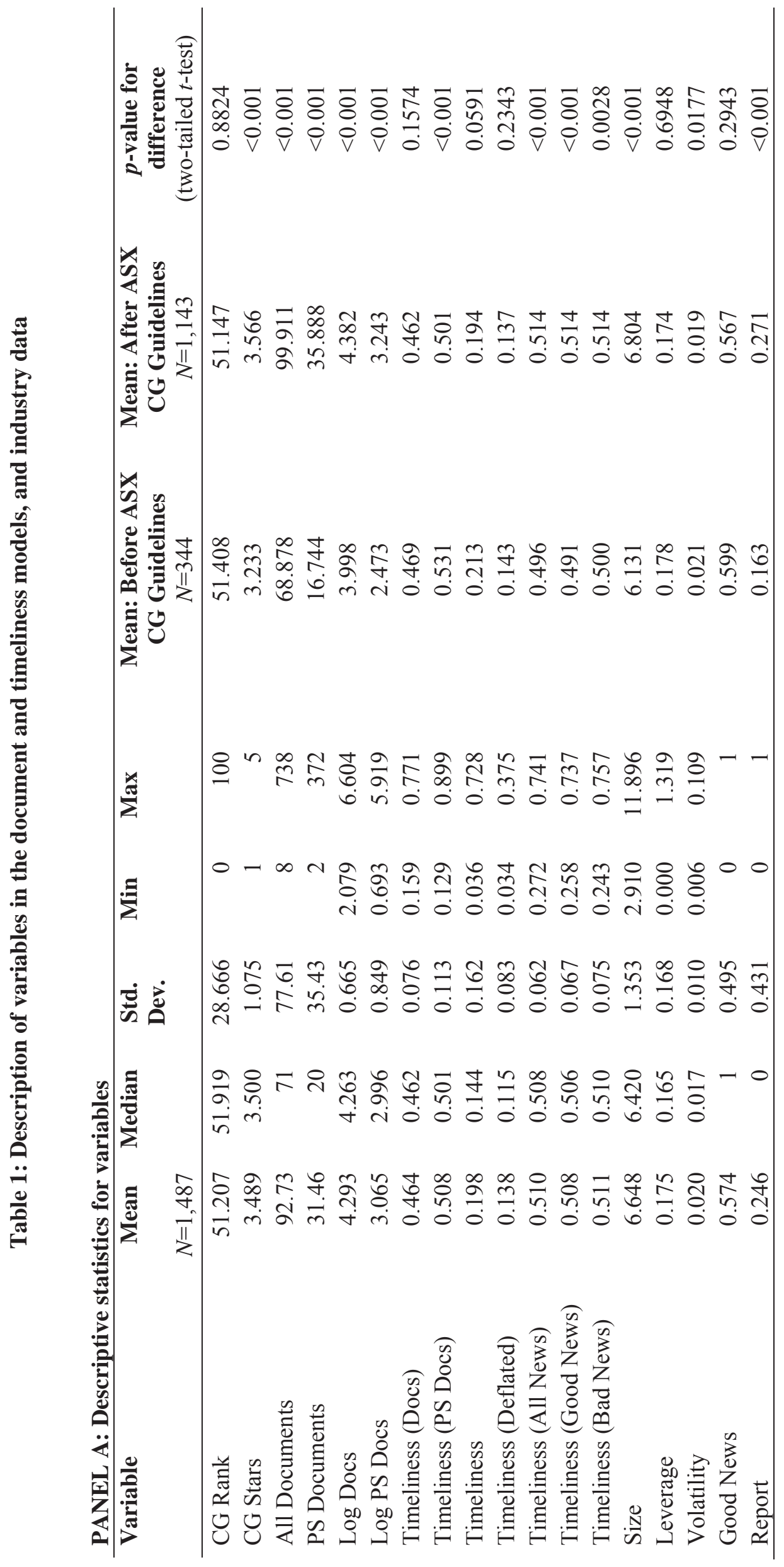




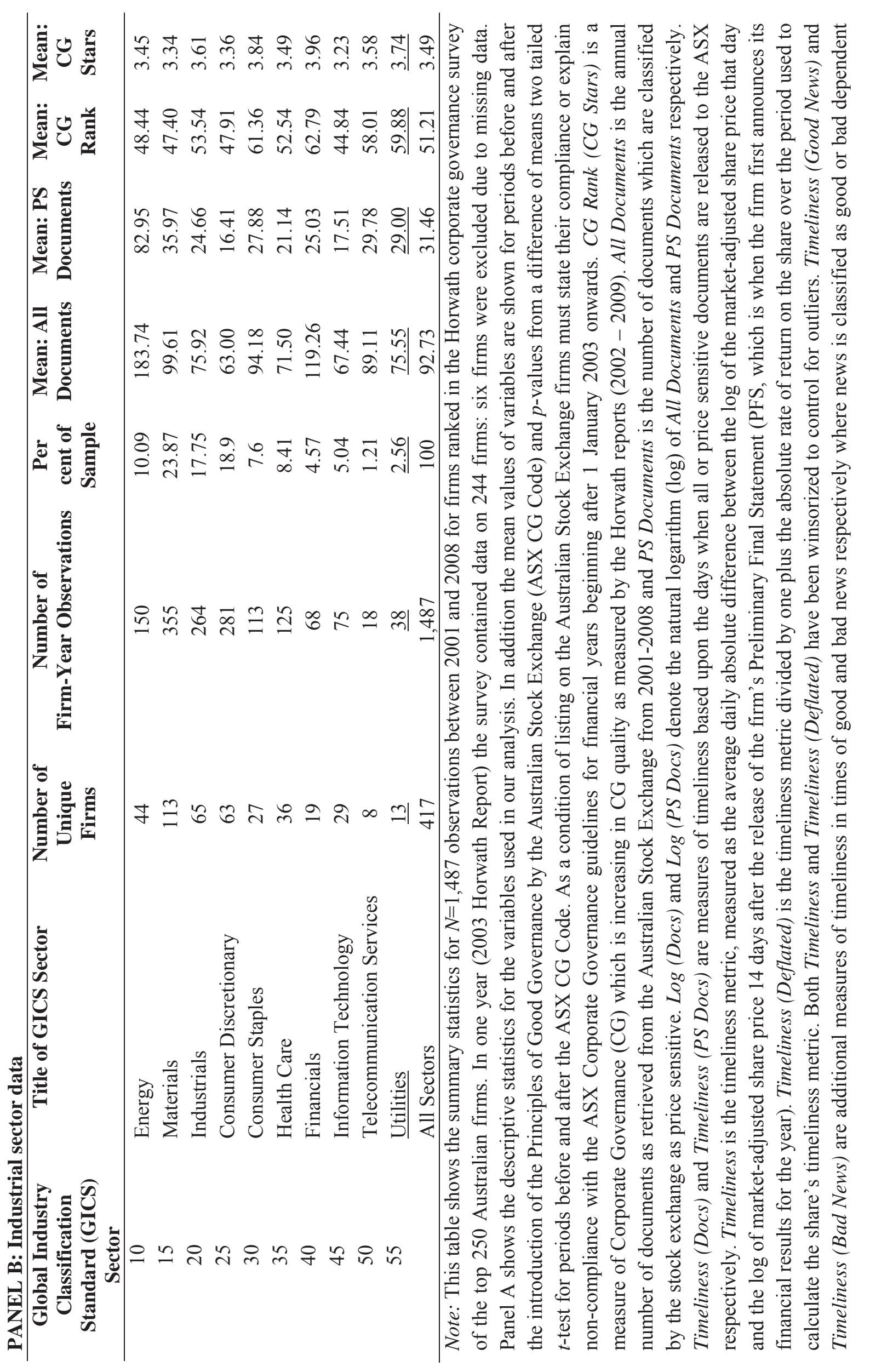




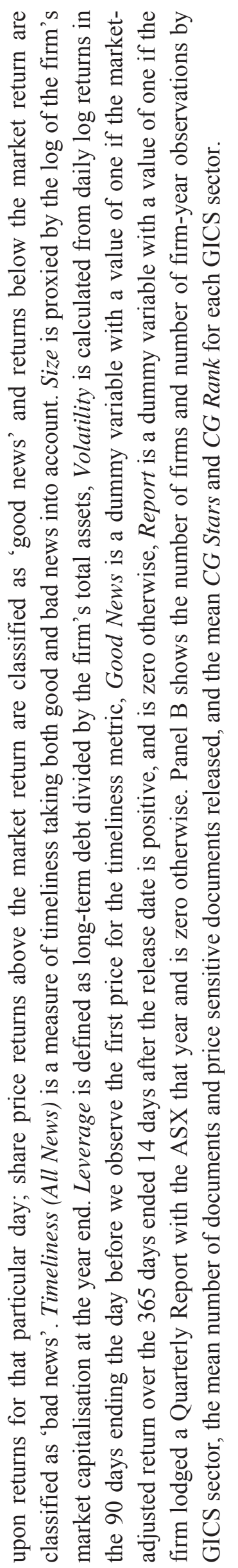




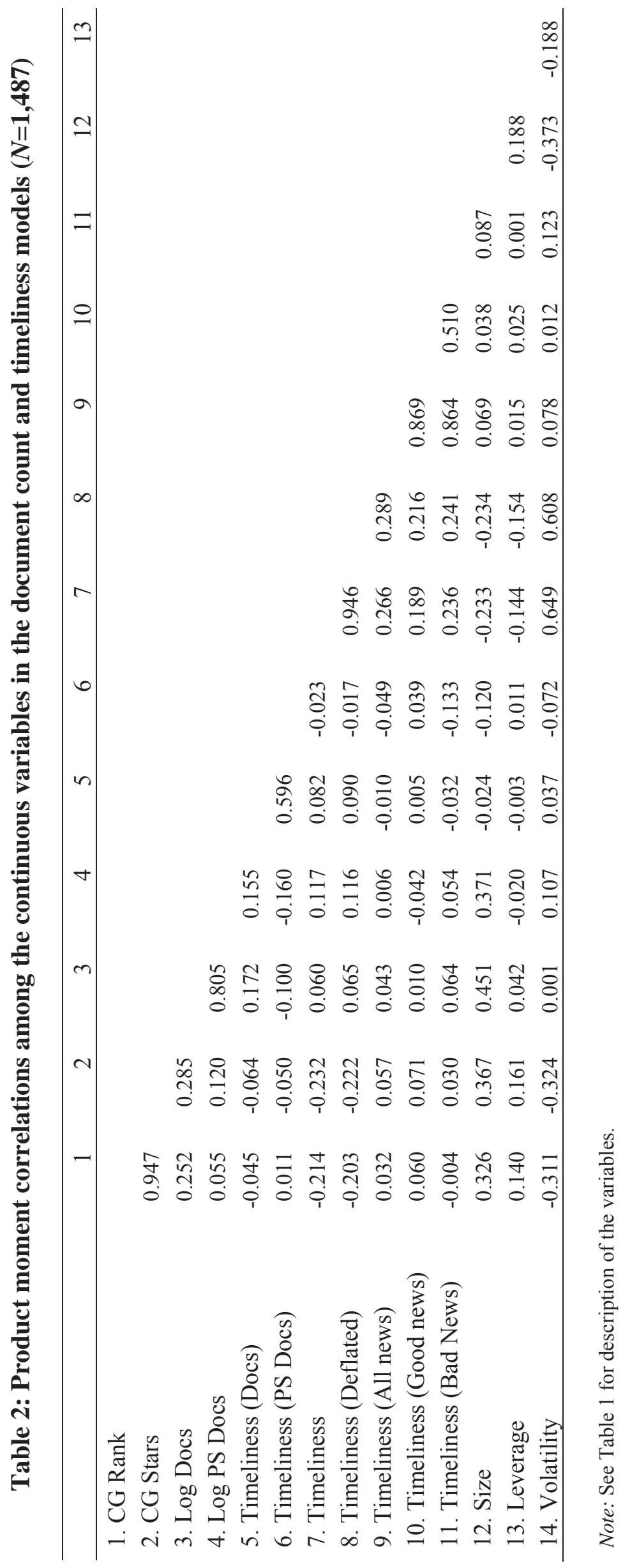




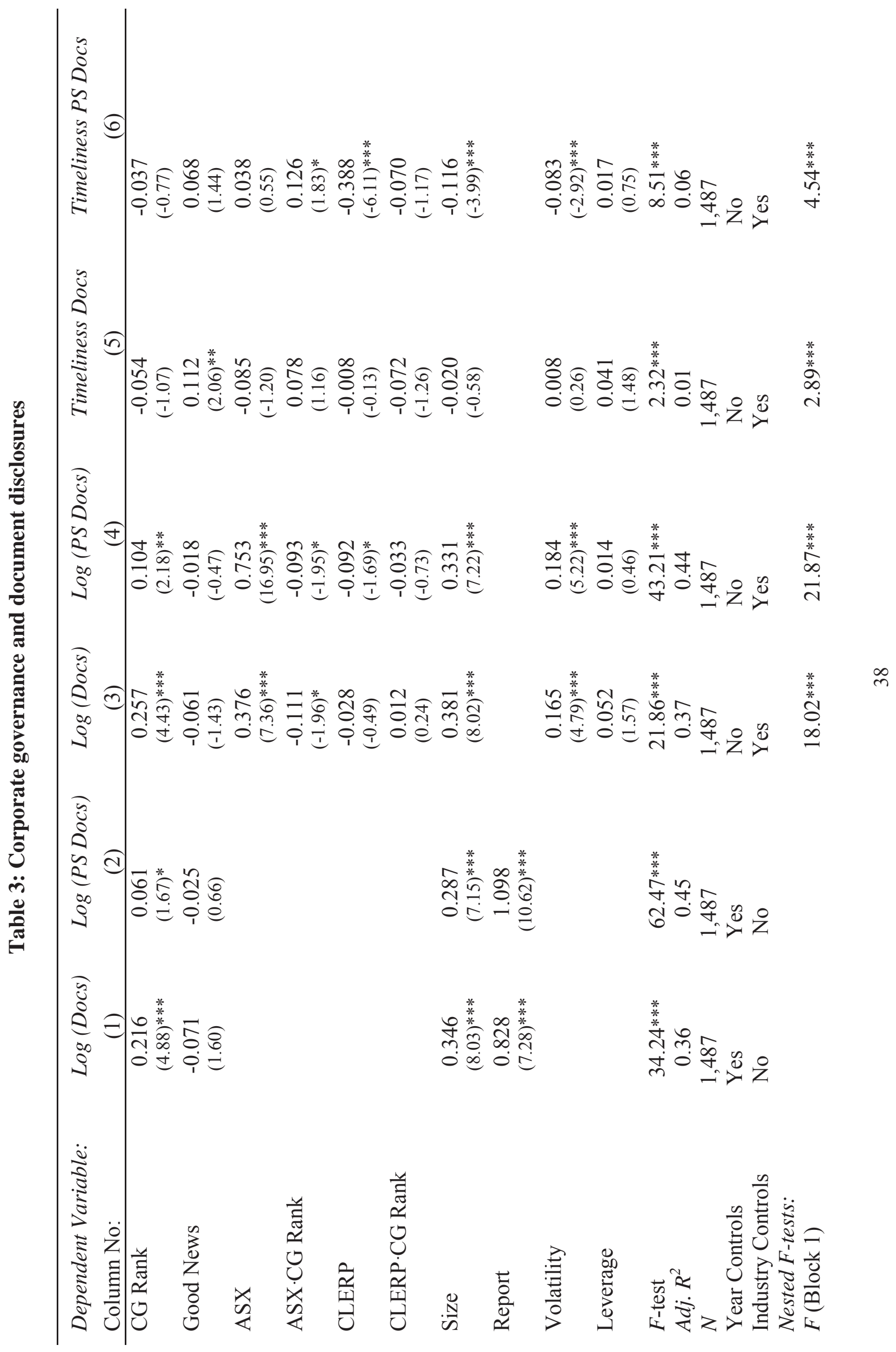




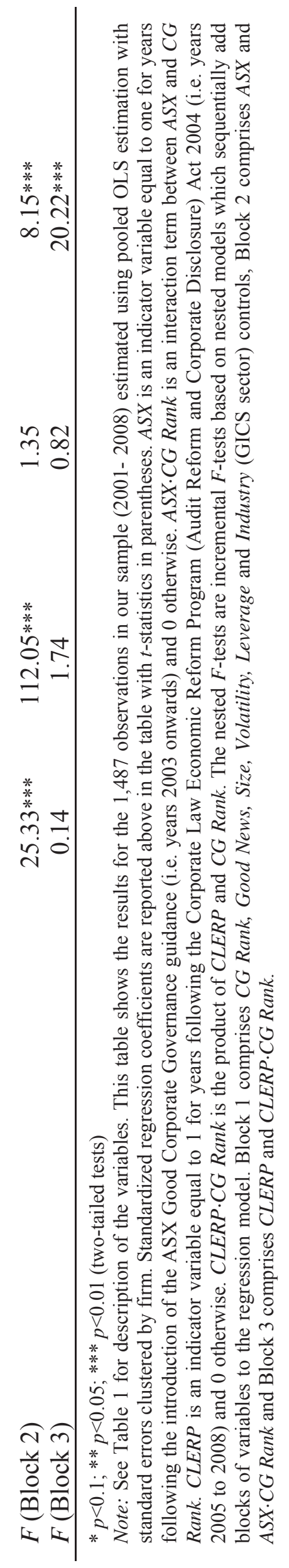




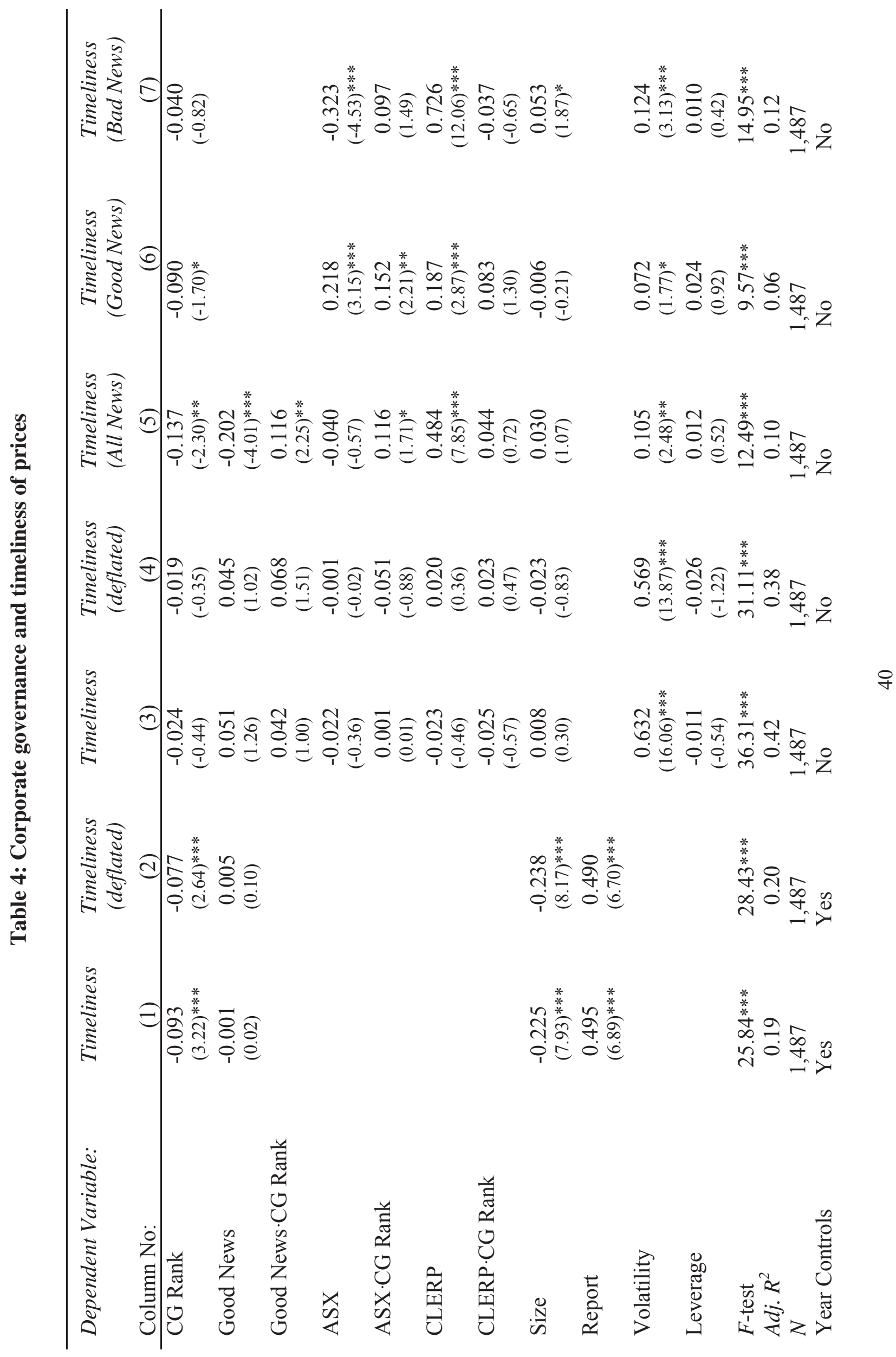




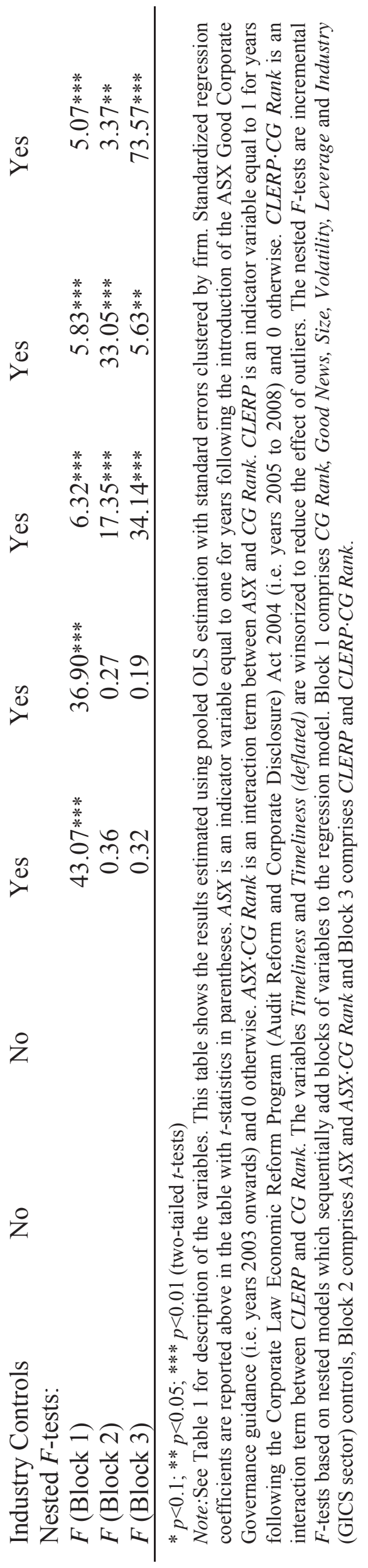




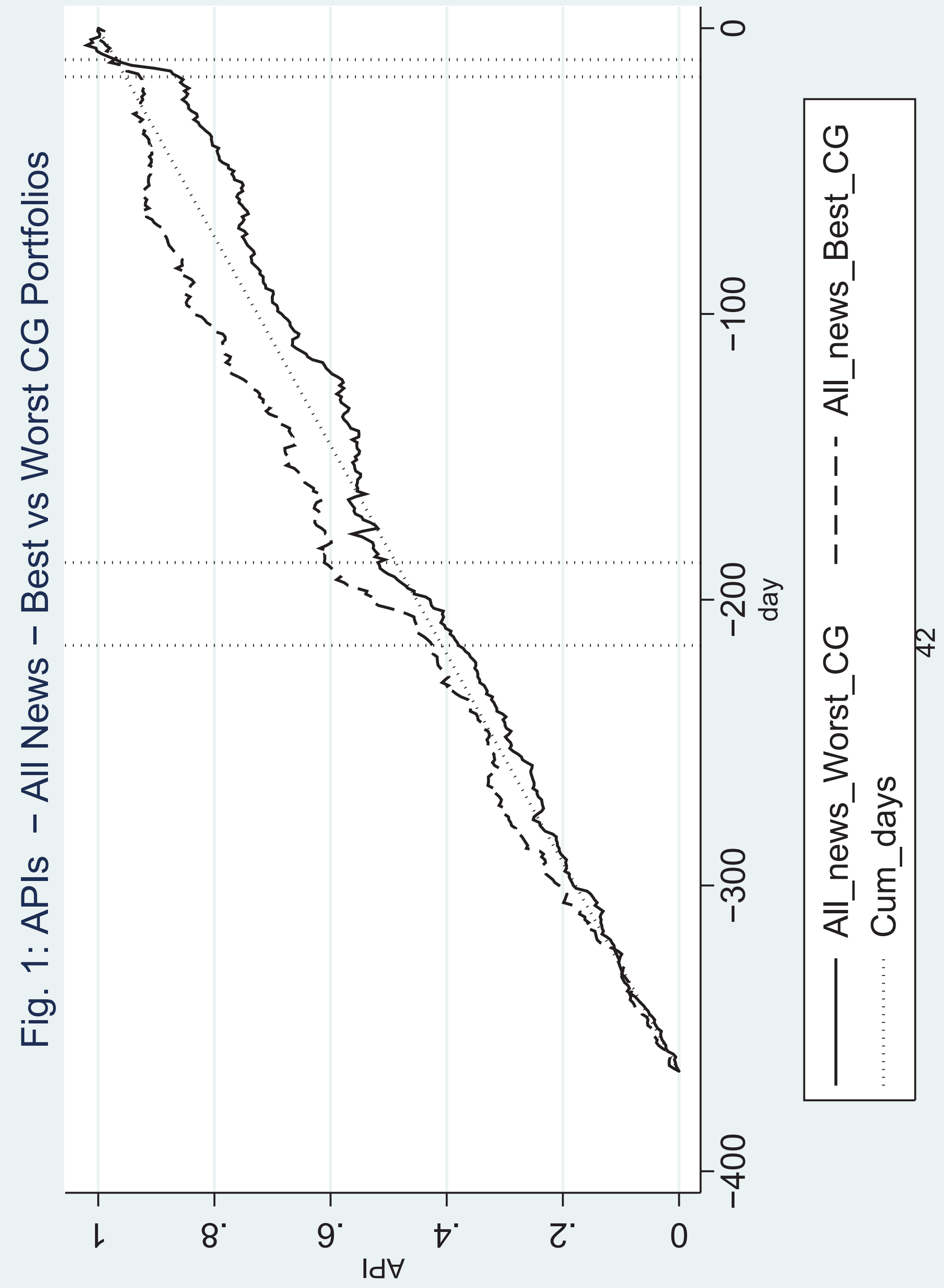




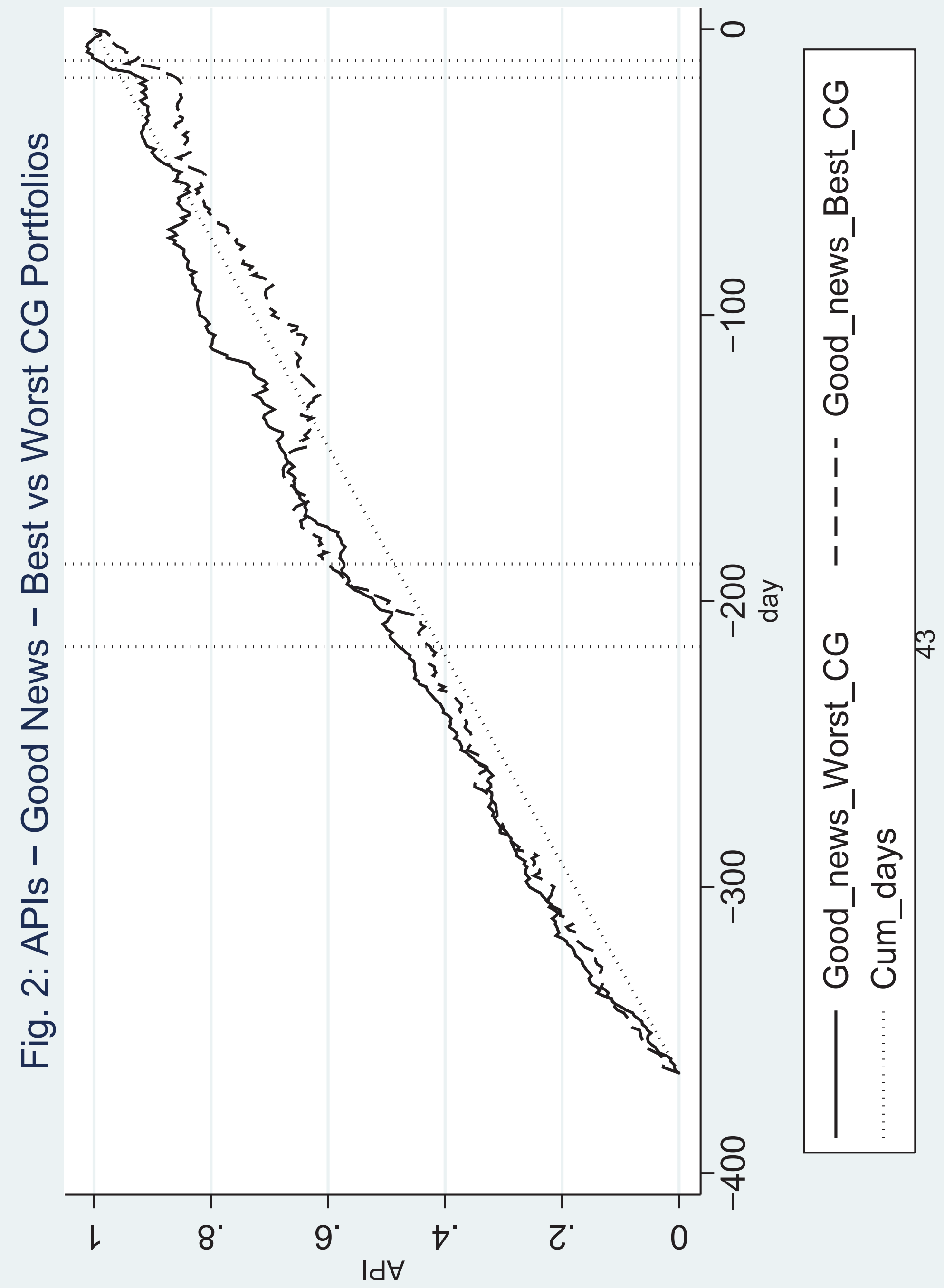




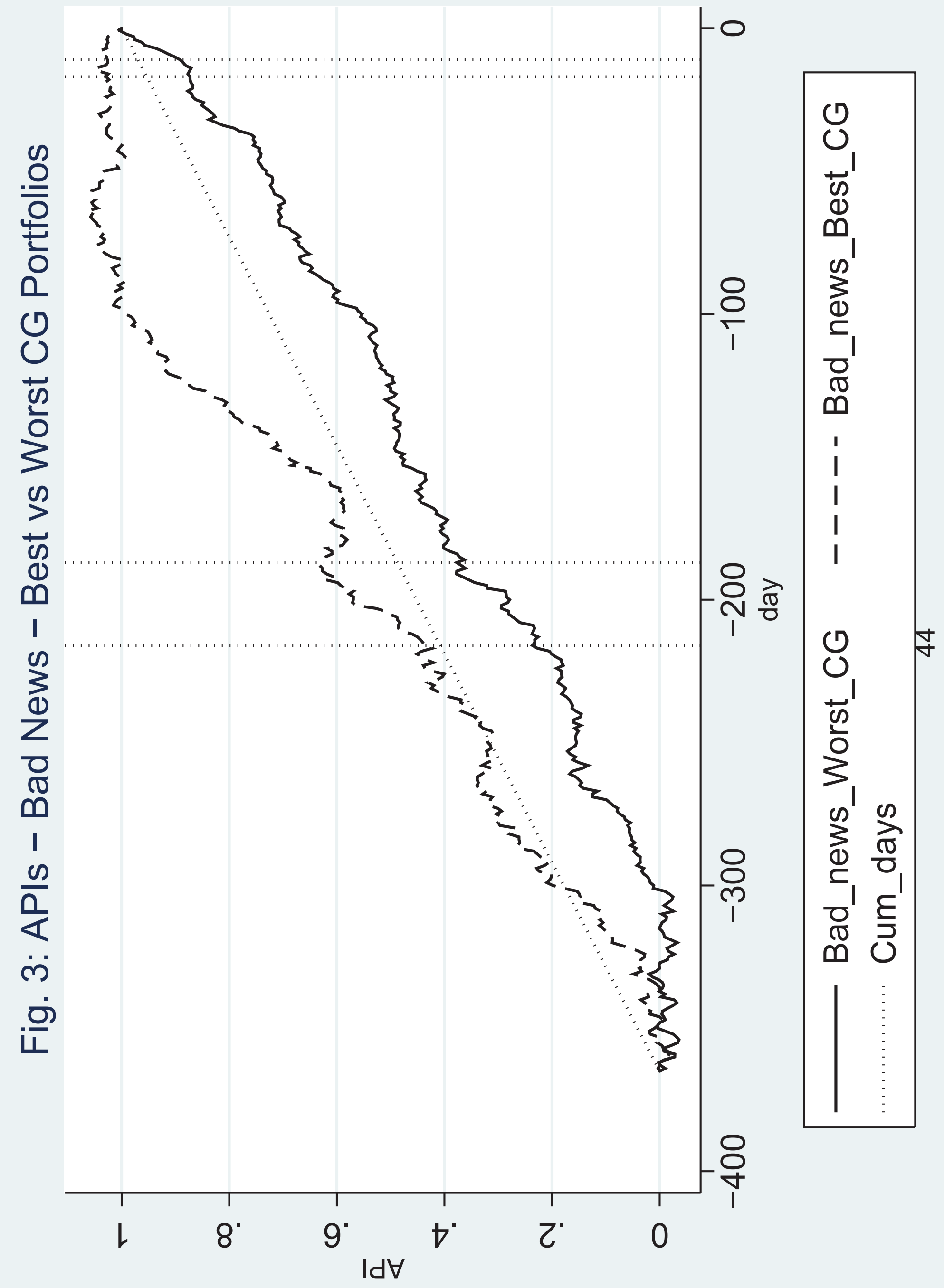




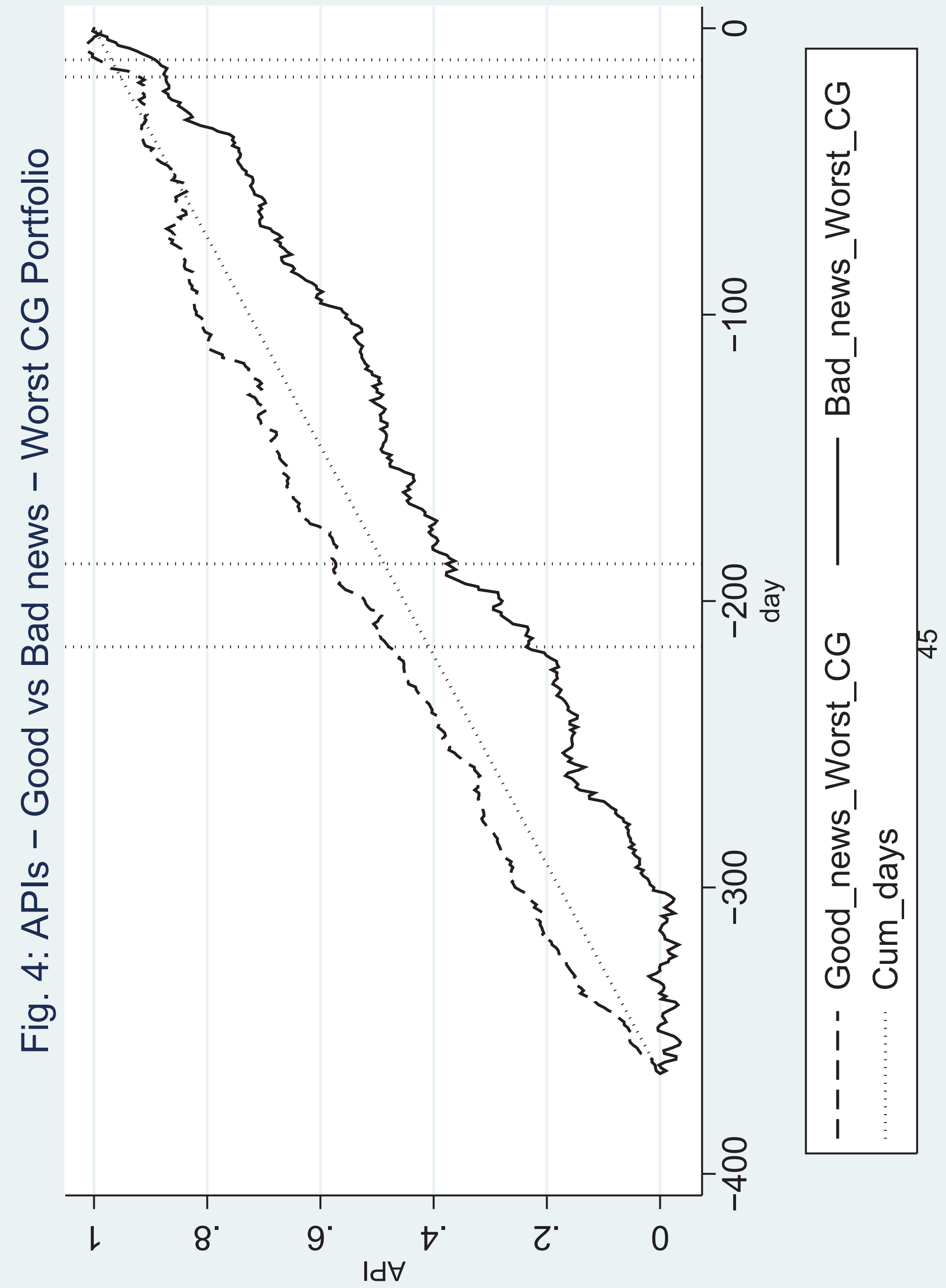




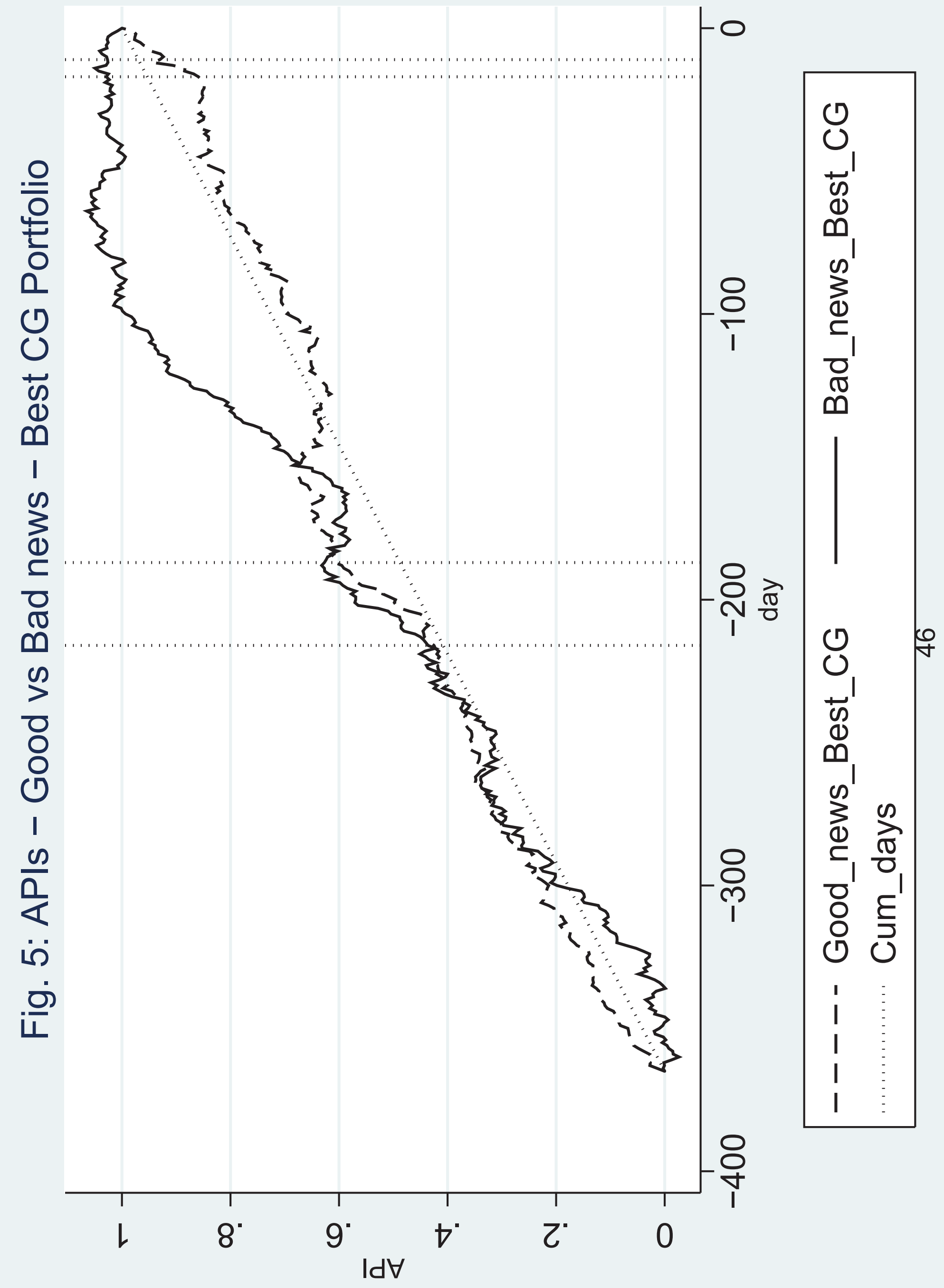




\section{Appendix: A resampling test of the statistical reliability of the difference in the mean timeliness calculated for two 'portfolios'}

It is one thing to observe a difference in a summary statistic, in the present case 'timeliness', for two portfolios, but another to decide whether the observed difference may be due to chance. We calculate this possibility by applying a simple resampling procedure.

Consider two portfolios, $P 1$ and $P 2$, comprising $N 1$ and $N 2$ securities respectively. Their combined portfolio comprises $N=N 1+N 2$ securities. We operationalise a portfolio's timeliness as the average difference between the portfolio's cumulative, market-adjusted price relative and its terminal value (of one) calculated over the 365 days from day -365 to day -1. (Note that the timeliness metric used here differs slightly from that used in tests at the level of the individual stock.) Next, calculate the statistic for $P 1$ and for $P 2$, and the difference observed between the two statistics; call this difference the experimental value (ev). The resampling procedure is designed to generate the distribution of ev if the allocation of the sample of firm-years to each portfolio were the result of chance. To generate this distribution, we conduct a sufficiently large number of trials. In the first trial, we randomly assign $N 1$ of the $N$ cases to the first pseudo portfolio, pseudo $P 1$, and assign all of the remaining cases (there are $N 2=N-N 1$ ) to pseudo $P 2$. We then calculate the difference in the statistic for pseudo $P 1$ and for pseudo $P 2$, which we call the control value (cv), and note whether $\mathrm{cv}$ is less than, equal to, or greater than ev. We conduct this resampling procedure 100,000 times. At the end of the resampling process we calculate the relative frequencies with which the three outcomes $(\mathrm{cv}<\mathrm{ev}, \mathrm{cv}=\mathrm{ev}, \mathrm{cv}>\mathrm{ev})$ occurred, and apply a one- or twotailed test as appropriate. 